\title{
Dry Mouth, CTCAE
}

National Cancer Institute

\section{Source}

National Cancer Institute. Dry Mouth, CT CAE. NCI Thesaurus. Code C143411.

A disorder characterized by reduced salivary flow in the oral cavity. 